\title{
Monitoring Energy Balance Through Clinical and Serum Biomarkers in Patients with Hmatologic Malignancies during Chemotherapy
}

\section{CHANG WON LEE}

Seoul National University Hospital

INHO KIM

Seoul National University College of Medicine, Seoul National University Hospital

YOUNGIL KOH

Seoul National University College of Medicine, Seoul National University Hospital

DONGYEOP SHIN

Seoul National University College of Medicine, Seoul National University Hospital

JUNSHIK HONG

Seoul National University College of Medicine, Seoul National University Hospital

DONG-HOON KIM

Korea University College of Medicine

\section{MI-RAE PARK}

Korea University College of Medicine

\section{SUN-MOK HONG}

Seoul National University Hospital

\section{YEJI LEE}

Seoul National University Hospital

Kwan Sik Seo ( $\square$ snurm@daum.net)

Seoul National University College of Medicine, Seoul National University Hospital

\section{Research Article}

Keywords: energy balance, cancer cachexia, biomarker, CXCL13, GDF15, leptin, hematologic cancer, resting energy expenditure, malnutrition

Posted Date: November 30th, 2021

DOI: https://doi.org/10.21203/rs.3.rs-1065861/v1

License: (c) (1) This work is licensed under a Creative Commons Attribution 4.0 International License. Read Full License 


\section{Abstract}

Background: Many cancer patients experience energy imbalance due to the tumor or chemotherapy-related side effects. Chemotherapy could make significant metabolic changes leading to energy imbalance. However, the variations in energy input, metabolic rate, and physical activity are not known in detail. This study aimed to identify changes in energy balance components and serum biomarkers during chemotherapy of patients with hematologic cancer.

Methods: This prospective study included 40 patients with hematologic malignancies hospitalized for chemotherapy. Energy balance components, physical function, and serum biomarkers, such as albumin, total protein, CXCL13, GDF15 and leptin, were measured weekly after chemotherapy for 3 weeks.

\section{Results:}

Significant body weight loss, representing negative energy balance, occurred at 2 and 3 weeks after chemotherapy. A statistically reduced oral intake was observed at week three. However, total energy intake did not show any statistical change during the study period due to parental support. Resting energy expenditure statistically decreased according to the Harris-Benedict (HB) equation, but not for the Penn State University (PSU) equation. Physical activity measured by daily steps showed no statistical difference. However, physical function according to the DEMMI score indicated a significant decrease at 3 weeks. Over half of the patients $(65.0 \%, n=26)$ were found to have at least one of energy balance problem according to subgroup classification.

Our serum biomarker analysis demonstrated significant differences in serum albumin, total protein, CXCL13, and GDF15 levels, with the exception of leptin. All three subgroups exhibited statistically significant decreases in albumin and total protein. However, only CXCL13 levels in the weight loss group and GDF level in the anorexia and impaired physical function groups were found to be significantly altered by subgroup analysis.

Conclusions: The results indicated that $65 \%$ of hematologic cancer patients suffered from energy imbalances during chemotherapy associated with weight loss and anorexia. Significant changes in albumin, total protein, CXCL13, and GDF15 were found. Additionally, subgroup analysis suggested that CXCL13 and GDF15 were associated with weight loss and appetite loss, respectively. Monitoring the energy balance of clinical and serum biomarkers together can help identify the need for nutritional intervention in patients undergoing chemotherapy.

\section{Background}

The homeostatic state achieved when energy consumption and intake are the same is called energy balance [1]. Humans consume energy through the intake of food and drink and expend energy through resting energy expenditure (REE), thermic effect of food (TEF), and activity energy expenditure (AEE). The cardinal feature of nutrition and metabolism is the balance of energy intake and energy expense, and when the level of energy balance is biased to one side, it appears as body weight change [2]. If the energy input is greater than the expenditure, it leads to weight gain, resulting in obesity. There is a growing risk associated with obesity, which causes many diseases and health costs.[3]. On the contrary, if the energy input is less than the energy expenditure, weight loss and malnutrition will occur. Malnutrition is currently raising considerable socioeconomic problems in long-term care facilities and is known to be up to $85 \%$ prevalence rate [4]. 
More factors are involved in the energy balance issues in most cancer patients. There are metabolic alterations related to chemotherapy, nutritional treatment and the tumor itself [5]. A previous study reported that the frequency of weight loss and malnutrition ranged from 31-87\% depending on the tumor site and stage. [6]. The prevalence of malnutrition in patients with cancer was $44.1 \%$ for inpatients and $27.7 \%$ for outpatients in Europe [7]. Among patients with hematologic cancer, the proportion of malnourished patients with nutritional support was $44.5 \%$, which is less than half [7]. Not only cancer itself, but also chemotherapy, an important part of cancer treatment, has multiple effects on energy balance. It can directly affect protein turnover, carbohydrate and lipid metabolism in cellular level and cause nutrition impact symptoms such as nausea, vomiting, appetite loss and mucositis. [8]. As a result, cancel-related cachexia is caused by treatment-induced metabolic changes as well as reduced energy intakes. [9]. This also applies to cachexic patients experiencing functional dysfunctions, such as physical inactivity, decreased muscle strength, and exercise capacity [10]. During the chemotherapeutic treatment of acute leukemia, a high frequency of weight and muscle loss is likely to play an important role in disease prognosis [11]. Since a weight loss during cancer treatment causes fewer completed cycles of chemotherapy, it eventually reduces the survival rate.[12]. Conversely, patients receiving adjuvant chemotherapy for breast cancer have a tendency to gain weight later[13]. Because weight gain during chemotherapy in breast cancer patients is reported to be a worse prognosis factor, as a result, both positive and negative energy balance, have been associated with lower survival rates and quality-of-life (QoL) outcomes. [14].

Resting energy expenditure defined as the extent of calories required for a 24 hour by the body without active movement. This parameter is generally used to describe an individual's metabolic status and can be measured by indirect calorimetry (IC). [15]. Although accurate, this method is technically difficult and time consuming. In addition, specialized equipment and skilled personnel are required to do this. [16]. Alternatively, there are other methods for estimating REE through formula-based equations, such as the Harris-Benedict equation (HBEq) [17]. In clinical practice, the predictive REE is widely used despite its limited accuracy because the predictive equations are easily accessible without the need for specialized equipment and appliances [15]. According to previous studies, the REE measured in most healthy populations is within $10 \%$ of the predicted REE, which is regarded normal metabolic status. c [18]. However, one systematic review showed that predictive EE equations available to date do not generally agree with the results of IC in patients with cancers. This could be because these patients are exposed to clinical factors that change the metabolic rate which are not considered in the predictive equations. [19].

In addition to measuring the patient's metabolic status, serum albumin and pre-albumin have been typically used as laboratory indicators to check the patient's nutritional status. However, changes in body hydrostatic pressure due to transition in body posture can lead to misunderstanding that the albumin level is incorrectly raised or lowered.

Albumin levels are also associated with lower levels of infection, hepatic failure, and cancer. Because pre-albumin is broken down in the kidneys, any renal dysfunction can increase serum levels of pre-albumin regardless of nutritional alterations [4]. Previous studies reported decreases in body weight, albumin, and physical activity during chemotherapy in patients with acute leukemia, but only included less than 10 patients [20,21]. Studies on the frequency of development of energy imbalance in hematologic cancer patients undergoing chemotherapy are not yet sufficient. In addition, there is still a lack of biomarkers that can quickly reflect the energy balance for timely nutrition intervention.

The overall energy balance, represented by weight change, is known to be negative during chemotherapy. However, changes in energy input, expenditure, and physical activity are not known comprehensively. In addition, serum biomarkers associated with energy balance components have not been established. The aim of our study was to 
identify detailed changes in energy balance components and the relationship between serum biomarkers and energy balance components in patients with hematologic cancer undergoing chemotherapy.

\section{Methods}

\section{Participants and methods}

This study was a prospective study of patients with hematologic malignancy who were admitted between January 14 and December 21, 2020, for chemotherapy at our institution. The inclusion criteria for participation were (1) patients with hematologic cancer, (2) age $\geq 18$ years with communicable disease, and (3) scheduled chemotherapy treatment in the hospital for at least 3 weeks. The exclusion criteria were (1) severe systemic diseases that limited physical activity, (2) serious complications that required intensive care, (3) severe psychological problems, and (4) impaired cognition or communication. This study was approved by our Institutional Review Board. Informed consent was obtained from all patients.

Demographic data (age, sex, height, and weight), clinical information (type of hematologic malignancy, choice of chemotherapy, body temperature, and respiratory rate) were extracted from electronic medical records. All participants were inpatients, and baseline assessments were conducted before chemotherapy. Energy balance components, physical function levels, and laboratory tests were measured weekly after starting the administration of systemic chemotherapy until three weeks. Self-questionnaire surveys were also conducted on the general nutritional state and QoL of participants at baseline and 3 weeks after chemotherapy. We used the Korean version of the Scored Patient-Generated Subjective Global Assessment (PG-SGA), the European Organization for Research and Treatment of Cancer Quality-of-Life Core Questionnaire 30 version 3.0 (EORTC QLQ-C30), and EuroQol-5 dimension (EQ5D) (Fig. 1). Two patients were excluded because of their refusal during the study period (not shown in Fig. 1).

\section{Clinical outcome variables}

This study examined components related to the energy balance as follows: We estimated the overall energy balance through weight change as a result of energy intake and expenditure. Total energy intake was calculated by summing the oral intake and parental nutrition support. Components related to energy expenditure were obtained in daily steps and predictive REEs. Predictive REEs were calculated using the Harris-Benedict (HB) and Penn State University (PSU) equations. The HB and PSU equations were as follows:

Harris-Benedict (HB) equation [22]

Male: BMR (Basic Metabolic Rate) $(\mathrm{kcal} / \mathrm{day})=66.5+13.8 \times$ weight $(\mathrm{kg})+5.0$ x height $(\mathrm{cm})-6.8 \times$ Age

Female: BMR $(\mathrm{kcal} /$ day $)=655.1+9.6 \times$ weight $(\mathrm{kg})+1.8 \times$ height $(\mathrm{cm})-4.7 \times$ age

Penn State University (PSU) equation (2003a version) [23]

$\operatorname{REE}(\mathrm{kcal} /$ day $)=0.85 \times \mathrm{HB}+33 \times \mathrm{VE}(\mathrm{L} / \mathrm{min})+175 \times \operatorname{Tmax}\left({ }^{\circ} \mathrm{C}\right)-6433$

* VE = minute ventilation $(\mathrm{L} / \mathrm{min})$

* Tmax $=$ maximum body temperature $\left({ }^{\circ} \mathrm{C}\right)$ in the previous $24 \mathrm{~h}$ read from vital sign flow sheets. 
The parameters were obtained from the electronic medical records. In addition, the Morton Mobility Index (DEMMI) score as a mobility instrument provides clinicians with a valid interval-level method for accurately measuring and monitoring mobility levels in an acute hospital setting [24]. A trained physical therapist evaluated the patients' body functions using the DEMMI score.

Three cytokines (CXCL13 (CXC motif chemokine ligand-13), GDF15(growth/differentiation factor-15), and leptin) were selected as the biomarker candidates associated with cancer and energy regulation. CXCL13 and GDF15 have been proposed to be serum protein biomarkers for the progression of diverse types of cancer [26-29]. Additionally, it has been hypothesized that they are associated with energy balance regulation in animal studies [30-32]. Laboratory findings, including serum biomarkers (serum total protein, albumin, CXCL13, GDF15, and leptin) associated with energy balance, were obtained at baseline levels and measured weekly for 3 weeks. Leptin is a wellknown energy regulator that has been reported to be associated with cancer development and progression via multiple signaling pathways [25].

The PG-SGA is widely used in clinical and research as a screening tool to determine the nutritional status of patients with cancer through interviews and clinical aspects of patients without instrumental measurement or laboratory findings. The PG-SGA score, which is categorical, is a continuous measure. The higher the score, the greater the risk of malnutrition [33]. Subjective nutritional status and overall evaluation of patients were followed up before treatment and at the third week of treatment.

The EORTC QLQ-C30 was intended to assess the physical, psychological, and social functions of patients with cancer. The questionnaire is composed of global health status/QoL, five functional scales (physical, role, social, emotional, and cognitive), and nine symptom scales (fatigue, nausea/vomiting, pain, dyspnea, insomnia, appetite loss, constipation, diarrhea, and financial difficulties). All the scales and single-item measures ranged in scores from 0 to 100 by linear transformation. A high score on the global health and function scales out of 100 indicated a high/health level of QoL or functional status. In contrast, a high symptom scale score indicates a high level of symptomatology/problems [34].

The EQ-5D self-report descriptive system evaluates health-related QoL measures in five dimensions. It comprises one question for each of the following: mobility, self-care, usual activities, pain/discomfort, and anxiety/depression [35]. A validated Korean version of the EQ-5D, included answering the five-item descriptive system and TTO valuation for calculating the EQ-5D index score [36]. The EQ-5D index score ranged from 1 (the highest) to -0.171 (the lowest). One indicates the most complete health condition, and a lower score represents a poorer condition.

\section{Subgroup analysis}

Nausea and vomiting are the most common immediate manifestations of the administration of many chemotherapeutic agents, resulting in decreased oral intake and weight loss [37]. In a previous study, approximately $25 \%$ of cancer patients undergoing hematopoietic stem cell transplantation (HSCT) had a significant reduction in the DEMMI score and did not recover until 3 weeks [38]. We performed a subgroup analysis by defining individuals with energy imbalance and decreased physical function. Participants were divided into significant weight loss (SWL), reduced oral intake (ROI), and impaired physical function (IPF) groups.

\section{1) Significant weight loss (SWL) group}

Patients with more than $5 \%$ loss of stable body weight over the past 6 months, or a body mass index (BMI) less than $20 \mathrm{~kg} / \mathrm{m}^{2}$ and ongoing weight loss of more than $2 \%$ are classified as having cachexia [39]. This could 
distinguish patients who experienced substantial weight loss during the study period by referring to the definition of cancer cachexia. We categorized patients into the SWL group based on the following criteria: more than $5 \%$ weight loss or $2 \%$ loss in BMI 20 or lower in weight measured over a 3-week follow-up period compared to the value of their baseline body weight.

\section{2) Reduced oral intake (ROI) group}

According to the Nutrition Guideline for Cancer Patients, cancer patients undergoing chemotherapy are advised to consume more than $80 \%$ of their estimated energy requirements. Food intake is considered inappropriate if they consume less than $60 \%$ of their energy requirements for more than a week [24]. Patients with insufficient food intake at least once during the study period were included in the ROI group and we conducted statistical analysis for classifying patients into the ROI group. Total energy expenditure (TEE) may be predicted roughly by using rule of thumb and assuming TEE to be $30 \mathrm{kcal} / \mathrm{kg}$ in ambulatory patients [40]. As none of the participants were bedridden, $30 \mathrm{kcal} / \mathrm{kg}$ was uniformly applied to all participants for the TEE calculations.

\section{3) Impaired physical function (IPF) group}

We defined criteria for inclusion in the IPF group if the DEMMI score decreased by more than 10 points at least once during the study period. Previous studies have shown that the minimal clinically important difference in DEMMI is 10 out of 100 points. Therefore, a difference of more than 10 points is a clinically important change in patient mobility [24].

\section{Statistical analysis}

As a part of the longitudinal analyses, the data was analyzed at four different times (at baseline, at the first, second, and third week of follow-up) using one-way repeated measures ANOVA. Mauchly's test of sphericity (compound symmetry) was evaluated, and if found to be unsatisfactory, Greenhouse-Geisser or Huynh-Feldt correction was employed. Changes in energy balance components (body weight, oral/total intake, REE, steps), laboratory results (levels of serum total protein, albumin, CXCL13, GDF15, and leptin), and performance status (DEMMI) over time were measured using repeated measures ANOVA analysis.

For PG-SGA, QLQ-C30, and EQ5D, the average difference analysis was carried out using paired t-tests when the difference between baseline and follow-up tests was satisfied with normal distribution. If the normal distribution was not satisfied, the Wilcoxon signed-rank test was conducted. A chi-square test was used to compare the categorical variables. The statistical analyses were performed using SPSS software (version 26.0, IBM, NY, USA). The results were two-tailed, and a p-value $<0.05$ was considered statistically significant.

\section{Results}

\section{Demographics and characteristics of participants}

Table 1 shows the baseline characteristics of the patient cohort. The average age of participants was $47.75 \pm 16.90$ years, with 24 males (52.2\%) and 16 females (34.8\%). The most common type of hematologic malignancy was acute myeloid leukemia $(n=25,62.5 \%)$, followed by acute lymphoblastic leukemia $(n=7,17.5 \%)$, non-determined acute leukemia ( $n=5,12.5 \%)$ and the remaining three types (one for each). 
Table 1

Demographics and clinical characteristics of participants $(n=40)$

\begin{tabular}{|c|c|}
\hline Variable & Value \\
\hline Age (year), (Mean $\pm S D$ ) & $47.75 \pm 16.90$ \\
\hline \multicolumn{2}{|l|}{ Sex } \\
\hline Male & $24(52.2 \%)$ \\
\hline Female & $16(34.8 \%)$ \\
\hline \multicolumn{2}{|l|}{ Type of cancer $(n)$} \\
\hline AML & $25(62.5 \%)$ \\
\hline ALL & $7(17.5 \%)$ \\
\hline Acute bi-phenotypic leukemia & $1(2.5 \%)$ \\
\hline B-lymphoblastic lymphoma & $1(2.5 \%)$ \\
\hline CML & $1(2.5 \%)$ \\
\hline Non-determined leukemia & $5(12.5 \%)$ \\
\hline \multicolumn{2}{|l|}{ Phase of chemotherapy } \\
\hline Induction (including re-induction) & $29(72.5 \%)$ \\
\hline Consolidation & $11(25.0 \%)$ \\
\hline Palliative & $1(2.5 \%)$ \\
\hline Previous chemotherapy (times), (Mean \pm SD) & $0.97 \pm 1.44$ \\
\hline Number of drugs $(n)$, (Mean $\pm S D)$ & $10.33 \pm 4.24$ \\
\hline Type of antiemetic drugs $(n)$, (Mean $\pm S D$ ) & $0.65 \pm 0.53$ \\
\hline Chemotherapy duration (days), (Mean $\pm S D$ ) & $10.12 \pm 7.30$ \\
\hline
\end{tabular}

The most common phase of chemotherapy was the induction phase $(n=29,72.5 \%)$, mean duration of chemotherapy was 10.12 days, and the mean value of previous chemotherapy was $0.97 \pm 1.44$ times. On average, patients took 10.33 drugs during the study period, and 0.65 of them were identified as antiemetic drugs.

\section{Energy balance}

\section{1) Overall energy balance (Weight, PG-SGA)}

The weekly mean weight change of participants $(n=40)$ up to three weeks before and after chemotherapy are shown in Fig. 2a. There were significant weight losses in weeks 2 (66.13 to 64.70; $p=0.002$ ) and 3 (66.13 to 64.03; $p<0.001$, Fig. 2a). Fig. 2b indicates the changes in baseline and week 3 (W3) of the PG-SGA score. The score was found to be statistically significant (4.88 to 6.75; $p=0.015$, Fig. $2 b$ ). The follow-up result at W3 deteriorated, but no active intervention was required according to nutritional triage recommendations [41]. 


\section{2) Energy intake (oral intake, parental support, and total intake)}

Changes in the mean values of oral intake, parental support, and total intake at the baseline and weekly follow-ups after chemotherapy are shown in Fig. 3. Overall, oral intake decreased over time, and statistical significance was observed between baseline and W3 (1952.3 to 1663.9; $p=0.040$, Fig. 3a). The number of patients using parental support was one at baseline, five at week 1 (W1), five at week 2 (W2), and 7 at W3. The mean value of parental support increased and statistical significance was confirmed at baseline and W3 (27.0 to 205.6; $p=0.036)$ as with oral intake (Fig. 3b). The average value of total intake increased slightly in W1 (1979.2 to 2022.6; $p=0.741$ ) compared to the baseline, but gradually decreased in W2 and W3. Unlike the previous oral intake and total intake, no statistical difference was observed in all three points of W1, W2, and W3 when compared with baseline (Fig. 3c).

\section{3) Energy expenditure (REE-HB\&PSU, DEMMI, steps)}

The changes in REE using the HB equation and PSU equation are shown in Fig. 4a. It was observed that HB-BMR significantly decreased in W2 (1477.0 to 1457.5; $p=0.001)$ and W3 $(1477.0$ to $1449.3 ; p<0.001)$ compared with the baseline. In the case of PSU-REE, no statistical difference was found at W1, W2, and W3 compared with the baseline (Fig. 4a). The DEMMI score decreased over time after chemotherapy and appeared statistically significant in W3 compared to the baseline ( 91.6 to $82.9 ; \mathrm{p}=0.002$, Fig. $4 \mathrm{~b}$ ). The mean values of daily steps were 701 (95\% $\mathrm{Cl}$ : 3091093) at baseline, 796 (95\% Cl: 287-1306; p=0.446) at W1, 657 (95\% Cl: 266-1048; p=0.861) at W2, and 714 (95\% Cl: 327-1101; $p=0.953)$. The $p$-values obtained at $W 1, W 2$, and W3 were compared to the baseline, and none of them demonstrated statistical differences.

\section{Laboratory findings}

\section{1) Serum total protein, albumin}

The serum total protein and albumin levels are shown in Table 2. Mean values of both in baseline were found to be significantly changed compared to W1 ( $p<0.001 ;<0.001$ for total protein and albumin, respectively), W2 ( $p=0.009$; $0.005)$, and W3 $(<0.001 ;<0.001)$. The mean values of W2 in both serum levels showed slight increases without statistical significance compared to W1. 
Table 2

Changes in the laboratory results of total participants and three subgroups

\begin{tabular}{|c|c|c|c|c|c|c|c|}
\hline $\begin{array}{l}\text { Serum } \\
\text { biomarker }\end{array}$ & $\begin{array}{l}\text { Baseline } \\
\text { (Mean } \\
\pm S D)\end{array}$ & $\begin{array}{l}\text { Week } 1 \\
\text { (Mean } \pm S D \text { ) }\end{array}$ & $\begin{array}{l}\mathrm{p}- \\
\text { value }\end{array}$ & $\begin{array}{l}\text { Week } 2 \\
\text { (Mean } \pm S D \text { ) }\end{array}$ & $\begin{array}{l}\mathrm{p}- \\
\text { value }\end{array}$ & $\begin{array}{l}\text { Week } 3 \\
\text { (Mean } \pm S D \text { ) }\end{array}$ & $\begin{array}{l}\mathrm{p}- \\
\text { value }\end{array}$ \\
\hline \multicolumn{8}{|c|}{ Total patients $(n=40)$} \\
\hline $\begin{array}{l}\text { T. protein } \\
(\mathrm{g} / \mathbb{\nabla})\end{array}$ & $\begin{array}{l}6.51 \\
\pm 0.75\end{array}$ & $6.06 \pm 0.67$ & $<.001 *$ & $6.22 \pm 0.70$ & $0.009 *$ & $6.05 \pm 0.69$ & $<.001 *$ \\
\hline $\begin{array}{l}\text { Albumin (g/ } \\
\text { 『) }\end{array}$ & $\begin{array}{l}3.89 \\
\pm 0.49\end{array}$ & $3.60 \pm 0.49$ & $<.001 *$ & $3.70 \pm 0.41$ & $0.005^{*}$ & $3.54 \pm 0.45$ & $<.001 *$ \\
\hline \multirow{2}{*}{$\begin{array}{l}\text { CXCL13(ng/ } \\
\text { 『) }\end{array}$} & $147.47 \pm$ & $102.43 \pm 118.33$ & $0.021 *$ & $135.24 \pm 191.84$ & 0.628 & $116.76 \pm 147.96$ & 0.183 \\
\hline & 186.85 & & & & & & \\
\hline $\begin{array}{l}\text { GDF15 (ng/ } \\
\text { ఐ) }\end{array}$ & $3.57 \pm 2.37$ & $4.68 \pm 2.45$ & $0.016 *$ & $3.54 \pm 2.44$ & 0.926 & $3.78 \pm 2.33$ & 0.673 \\
\hline $\begin{array}{l}\text { Leptin (ng/ } \\
\text { 『) }\end{array}$ & $9.73 \pm 7.15$ & $7.79 \pm 4.16$ & 0.052 & $10.23 \pm 5.98$ & 0.687 & $8.34 \pm 4.09$ & 0.179 \\
\hline \multicolumn{8}{|c|}{ SWL group ( $n=13)$} \\
\hline 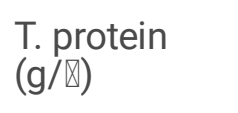 & $6.50 \pm 0.88$ & $6.09 \pm 0.80$ & 0.093 & $6.06 \pm 0.88$ & $0.045^{*}$ & $5.78 \pm 0.62$ & $0.006 *$ \\
\hline $\begin{array}{l}\text { Albumin (g/ } \\
\text { ఐ) }\end{array}$ & $3.88 \pm 0.57$ & $3.60 \pm 0.54$ & 0.140 & $3.59 \pm 0.46$ & 0.062 & $3.43 \pm 0.37$ & $0.015^{*}$ \\
\hline \multirow{2}{*}{$\begin{array}{l}\text { CXCL13(ng/ } \\
\text { 邓) }\end{array}$} & $120.97 \pm$ & $80.47 \pm 60.04$ & 0.101 & $70.85 \pm 56.65$ & $0.013^{*}$ & $46.57 \pm 32.49$ & 0.017 * \\
\hline & 88.55 & & & & & & \\
\hline $\begin{array}{l}\text { GDF15 (ng/ } \\
\text { 邓) }\end{array}$ & $3.53 \pm 2.87$ & $4.63 \pm 1.87$ & 0.123 & $3.40 \pm 2.17$ & 0.857 & $4.46 \pm 2.08$ & 0.354 \\
\hline $\begin{array}{l}\text { Leptin (ng/ } \\
\bigotimes)\end{array}$ & $8.89 \pm 5.00$ & $7.75 \pm 4.09$ & 0.379 & $10.56 \pm 6.13$ & 0.396 & $9.03 \pm 4.82$ & 0.917 \\
\hline \multicolumn{8}{|c|}{ ROI group $(n=20)$} \\
\hline 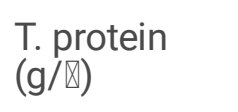 & $6.53 \pm 0.68$ & $6.09 \pm 0.63$ & $0.003 *$ & $6.30 \pm 0.75$ & 0.159 & $6.09 \pm 0.78$ & 0.052 \\
\hline $\begin{array}{l}\text { Albumin (g/ } \\
\text { \) }\end{array}$ & $3.92 \pm 0.37$ & $3.64 \pm 0.39$ & $0.007 *$ & $3.70 \pm 0.39$ & $0.030 *$ & $3.47 \pm 0.52$ & $0.002 *$ \\
\hline \multirow{2}{*}{$\begin{array}{l}\text { CXCL13(ng/ } \\
\text { 邓) }\end{array}$} & $123.42 \pm$ & $106.21 \pm 139.60$ & 0.331 & $132.31 \pm 194.10$ & 0.573 & $104.59 \pm 93.21$ & 0.573 \\
\hline & 179.47 & & & & & & \\
\hline $\begin{array}{l}\text { GDF15 (ng/ } \\
\bigotimes)\end{array}$ & $2.95 \pm 1.58$ & $4.91 \pm 3.04$ & $0.007 *$ & $3.49 \pm 2.70$ & 0.392 & $3.89 \pm 2.80$ & 0.194 \\
\hline
\end{tabular}

P-values were obtained from one-way repeated measures ANOVA to compare the mean values of weeks 1,2 , and 3 to baseline. T. protein, total protein; SWL, significant weight loss; ROI, reduced oral intake, IPF, impaired physical function; * $\mathrm{p}<0.05$ 


\begin{tabular}{|c|c|c|c|c|c|c|c|}
\hline $\begin{array}{l}\text { Serum } \\
\text { biomarker }\end{array}$ & $\begin{array}{l}\text { Baseline } \\
\text { (Mean } \\
\pm S D)\end{array}$ & $\begin{array}{l}\text { Week } 1 \\
(\text { Mean } \pm S D)\end{array}$ & $\begin{array}{l}\mathrm{p}- \\
\text { value }\end{array}$ & $\begin{array}{l}\text { Week } 2 \\
(\text { Mean } \pm S D)\end{array}$ & $\begin{array}{l}\mathrm{p}- \\
\text { value }\end{array}$ & $\begin{array}{l}\text { Week } 3 \\
(\text { Mean } \pm S D)\end{array}$ & $\begin{array}{l}\mathrm{p}- \\
\text { value }\end{array}$ \\
\hline $\begin{array}{l}\text { Leptin (ng/ } \\
\bigotimes)\end{array}$ & $9.57 \pm 8.61$ & $7.09 \pm 4.10$ & 0.160 & $9.83 \pm 5.12$ & 0.860 & $8.30 \pm 4.16$ & 0.456 \\
\hline \multicolumn{8}{|c|}{ IPF group $(n=21)$} \\
\hline 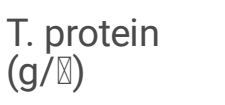 & $6.46 \pm 0.80$ & $5.82 \pm 0.72$ & $0.001^{*}$ & $6.17 \pm 0.78$ & 0.476 & $5.87 \pm 0.62$ & $0.016 *$ \\
\hline $\begin{array}{l}\text { Albumin (g/ } \\
\mathbb{Q})\end{array}$ & $3.80 \pm 0.47$ & $3.40 \pm 0.46$ & $0.004^{*}$ & $3.59 \pm 0.40$ & 0.209 & $3.34 \pm 0.33$ & $0.003^{*}$ \\
\hline \multirow{2}{*}{$\begin{array}{l}\text { CXCL13(ng/ } \\
\text { Q) }\end{array}$} & $148.93 \pm$ & \multirow[t]{2}{*}{$133.49 \pm 151.35$} & \multirow[t]{2}{*}{0.315} & \multirow[t]{2}{*}{$184.59 \pm 253.72$} & \multirow[t]{2}{*}{0.236} & \multirow[t]{2}{*}{$135.18 \pm 146.71$} & \multirow[t]{2}{*}{0.715} \\
\hline & 185.79 & & & & & & \\
\hline $\begin{array}{l}\text { GDF15 (ng/ } \\
\text { 邓) }\end{array}$ & $3.42 \pm 2.24$ & $5.37 \pm 2.79$ & $0.006 *$ & $4.08 \pm 2.52$ & 0.273 & $4.36 \pm 2.54$ & 0.201 \\
\hline $\begin{array}{l}\text { Leptin (ng/ } \\
\text { Q) }\end{array}$ & $9.56 \pm 8.47$ & $7.11 \pm 4.33$ & 0.130 & $9.49 \pm 5.30$ & 0.966 & $7.55 \pm 3.78$ & 0.255 \\
\hline $\begin{array}{l}\text { P-values wer } \\
\text { and } 3 \text { to base } \\
\text { physical func }\end{array}$ & $\begin{array}{l}\text { obtained fror } \\
\text { ine. T. protein } \\
\text { ion; *p }<0.05\end{array}$ & $\begin{array}{l}\text { one-way repeate } \\
\text { otal protein; SWL }\end{array}$ & $\begin{array}{l}\text { measure } \\
\text { significal }\end{array}$ & $\begin{array}{l}\text { ANOVA to comp } \\
t \text { weight loss: RO }\end{array}$ & $\begin{array}{l}\text { e the } n \\
\text { educes }\end{array}$ & $\begin{array}{l}\text { values of week } \\
\text { al intake, IPF, imf }\end{array}$ & $\begin{array}{l}1,2, \\
\text { aired }\end{array}$ \\
\hline
\end{tabular}

\section{2) Serum biomarker candidates (CXCL13, GDF15, Leptin)}

Changes in serum biomarkers are shown in Table 2. Compared to the baseline, a significant decrease was observed in CXCL13 at W1 (147.47 to 102.43; $p=0.021$ ), and a significant increase in GDF15 at W1 (3.57 to 4.68; $p=0.016$ ). No statistical significance was identified at W2 and W3 for CXCL13 and GDF15. In leptin, there was no statistical difference between the baseline and all three-time points (W1, W2, and W3).

\section{Subgroup analysis}

Subgroup analysis was performed by categorizing patients with energy imbalance, and $65.0 \%(n=26)$ of patients developed at least one energy imbalanced state. 13 patients were classified into the significant weight loss (SWL) group, 20 patients to the reduced oral intake (ROI) group, and 21 patients were classified as having impaired physical function (IPF). Seven patients did not belong to any group. Patients with overlapping energy balance or physical function problems are shown in the Venn diagram (Fig. 5).

\section{1) Significant weight loss (SWL) group $(32.5 \%, n=13)$}

Serum total protein at W2 (6.50 to $6.06 ; p=0.045)$, W3 (6.50 to 5.78; $p=0.006$ ), and albumin at W3 (3.88 to 3.43; $\mathrm{p}=0.015$ ) showed statistical differences. CXCL13 was the only biomarker candidate that was found to be statistically different in the SWL group. The mean value of CXCL13 decreased over time, and statistical differences were confirmed at W2 (120.97 to $70.85 ; \mathrm{p}=0.013)$ and at W3 (120.97 to 46.57; $\mathrm{p}=0.017)$ compared to the baseline (Table 2). Additionally, a significant reduction was observed from W1 to W3 (80.47 to 46.57; $\mathrm{p}=0.033$ ).

\section{2) Reduced oral intake (ROI) group $(50 \%, n=20)$}


There was a statistical difference in total protein at W1 (6.53 to 6.09; $p=0.003$ ) and in albumin at W1 (3.92 to 3.64 ; $p=0.007)$, W2 (3.92 to 3.70; $p=0.030$ ), W3 (3.92 to 3.47; $p=0.002)$. GDF15 was the only biomarker candidate that showed a significant difference in the ROI group. A statistical difference was seen at W1 (2.95 to 4.91; $p=0.007)$ compared to the baseline, but the mean value of GDF15 did not exhibit consistent change over time (Table 2). A statistical difference between W2 and W3 (4.91 to 3.49; $p=0.007)$ was also observed, and the direction of change was toward the baseline.

\section{3) Impaired physical function (IPF) group $(52.5 \%, \mathrm{n}=21)$}

Total protein and albumin showed statistical differences at W1 (6.46 to 5.82; $p=0.001,3.80$ to 3.40; $p=0.004$, respectively, for total protein and albumin) and $W 3$ (6.46 to $5.87 ; p=0.016,3.80$ to $3.34 ; p=0.003$, respectively). GDF15 was the only biomarker candidate that showed a statistical difference in the IPF group and the ROI group. The mean values of GDF15 were not consistent over time, and a statistical decrease was only found at W1 (3.42 to 5.37; $p=0.006$ ) compared with baseline. (Table 2).

\section{Quality-of-life (QLQ-C30, EQ-5D)}

QoL evaluations were performed twice, at the baseline and three weeks after chemotherapy, and the results are displayed in Table 3. Analyzing the QLQ-C30 indicated statistical improvement in the global health status/QoL category ( 40.3 to $52.5 ; p=0.001$ ), but no statistical difference was seen in the remaining functional and symptom scale items. The EQ-5D index score, a health-related QoL index, was also not found to be statistically significant. 
Table 3

Changes in EORTC QLQ-C30 and EQ-5D

\begin{tabular}{llll}
\hline Characteristics & Baseline & Week 3 & p-value \\
& $($ Mean \pm SD) & (Mean \pm SD) &
\end{tabular}

QLQ-C30 (n=36)

Global health status/QoL

$40.3 \pm 23.5$

$52.5 \pm 22.1$

$0.001^{*}$

Function scales

Physical functioning

$66.3 \pm 25.9$

$64.8 \pm 21.0$

0.705

Role functioning

$61.1 \pm 34.0$

$60.2 \pm 27.1$

0.854

Emotional functioning

$68.1 \pm 24.3$

$67.8 \pm 26.4$

0.959

Cognitive functioning

$81.9 \pm 25.0$

$78.2 \pm 22.8$

0.407

Social functioning

$54.2 \pm 36.4$

$51.4 \pm 31.2$

0.481

\section{Symptom scales}

\begin{tabular}{llll}
\hline Fatigue & $53.1 \pm 27.1$ & $50.0 \pm 25.0$ & 0.504 \\
\hline Nausea and vomiting & $21.3 \pm 23.8$ & $22.2 \pm 26.4$ & 0.874 \\
\hline Pain & $38.0 \pm 32.8$ & $34.7 \pm 27.4$ & 0.489 \\
\hline Dyspnea & $32.4 \pm 36.9$ & $30.6 \pm 30.2$ & 0.751 \\
\hline Insomnia & $34.3 \pm 34.3$ & $42.6 \pm 34.4$ & 0.221 \\
\hline Appetite loss & $50.0 \pm 29.3$ & $48.1 \pm 34.2$ & 0.786 \\
\hline Constipation & $21.3 \pm 22.8$ & $17.6 \pm 24.5$ & 0.473 \\
\hline Diarrhea & $24.1 \pm 27.2$ & $24.1 \pm 30.5$ & 0.986 \\
\hline Financial difficulties & $34.3 \pm 33.3$ & $31.5 \pm 30.8$ & 0.373 \\
\hline EQ-5D (n=35) & & & \\
\hline EQ-5D index & $0.757 \pm 0.207$ & $0.800 \pm 0.142$ & 0.170 \\
\hline $\begin{array}{l}\text { P-values were obtained from the t-test and Wilcoxon signed-rank test comparing the difference between } \\
\text { baseline and week 3. EORTC QLQ-C30, European Organization for Research and Treatment of Cancer Quality-of- } \\
\text { Life Questionnaire C30; QoL, quality-of-life, EQ-5D, EuroQol five-dimensional *p-value < 0.05 }\end{array}$ &
\end{tabular}

\section{Discussion}

Our study evaluated the energy balance components and serum biomarkers weekly for 3 weeks during and after chemotherapy in patients with hematologic cancer. In our study, 13 patients (32.5\%) experienced important weight loss at 2 weeks after chemotherapy. Seven patients (53.8\%) also experienced anorexia. This result was consistent with a previous study that revealed weight loss in $53-58 \%$ of patients after chemotherapy. They also reported that patients who lost their body weight experienced more appetite loss [42, 43]. This may be associated with the effects 
of several chemotherapy agents on muscle catabolism, oxidative stress, and fat lipolysis, eventually resulting in weight loss [44].

A statistical decrease in oral intake appeared at week three, which was later than the weight loss. Because some patients who showed severe oral intake loss were supported by parental nutrition, there was no statistical decrease in total energy input compared to baseline during our study period. Nevertheless, losing weight may be due to malabsorption and metabolic changes caused by the tumor itself and chemotherapy. A previous study suggested that cancer-associated cachexia is not solely caused by reduced food intake, but also by multi-organ related metabolic disorders [45]. In addition, chemotherapeutic agents play various roles in energy balance disorders such as appetite loss, diarrhea, malabsorption, and metabolic changes [46, 47]. In addition, the PG-SGA score, a subjective evaluation of energy balance, worsened at 3 weeks after chemotherapy compared to the baseline (4.88 to 6.75). According to the nutritional triage recommendation, both PG-SGA scores before and after receiving chemotherapy required nutritional intervention, such as dietitian consultations, but did not deteriorate to severe grade (PG-SGA score $\geq 9$ ) after chemotherapy [41].

Not surprisingly, physical activity, a part of energy expenditure, also appears to be affected by cancer treatment. Bryant et al. reported that acute leukemia patients frequently expressed fatigue during and after treatment. This was connected to lowered physical activity, directly influencing health-related quality-of-life [48]. In our study, we measured the daily steps as an index representing physical activity. Although the difference was not statistically significant, the mean value tended to decrease. Furthermore, when the physical function state was evaluated using DEMMI, a statistical decrease was observed at three weeks after chemotherapy. This change was a week later than the previous study mentioned above, conducted in patients who underwent HSCT [38]. However, the proportion of patients with impaired physical performance was $52.5 \%(n=21)$. Galati et al. reported a statistical reduction in REE (another component of energy expenditure) via IC after the first chemotherapy cycle in patients with acute leukemia [49]. This difference was not substantiated by Lesbours et al. whose research shows that there was no statistical difference in the REE measured via IC 28 days after induction chemotherapy in ALL patients [21] Both studies tended to underestimate REE when predicting it using the HB equation compared to REE measurement via IC [21, 49]. The HB equation treats the relationship between resting metabolic rate and body weight as linear [50]. In our study, the significant decrease in mean body weight may have affected REE prediction because it was the only variable of the HB equation during the study period. In addition to the HB equation for REE prediction, the PSU equation uses more variables related to clinical data (minute ventilation and body temperature). The American Dietetic Association has conducted systematic reviews on critically ill patients and concluded that the Penn State equations have a higher accuracy rate than other equations [50]. There was no statistical difference in REE prediction using the PSU equation, and it was difficult to accurately evaluate the change in REE during and after chemotherapy in our study.

Significant changes in the levels of serum albumin, total protein, CXCL13, and GDF15 were observed in our study, except leptin. Although all three subgroups exhibited statistically significant decreases in albumin and total protein, only CXCL13 in the SWL and GDF15 in the ROI and IPF groups were found to be significantly different in the subgroup analysis.

According to a meta-analysis, biomarkers of malnutrition, serum albumin, and total protein among subjects at high risk of malnutrition were significantly lower than those at a low risk [51]. Hypoalbuminemia results from malnutrition and reflects an inflammatory state. It hinder proper response to chemotherapy and is associated with decreased lifespan and poor quality-of-life[52]; therefore, hypoalbuminemia is a strong predictor of poor clinical

Page 13/24 
outcomes in many medical conditions, including solid and hematologic cancers [53]. In our study, serum total protein and albumin levels showed statistically significant decreases in all participants and all subgroups. These significant reductions in serum albumin levels occurred before weight loss. However, in all groups, the average

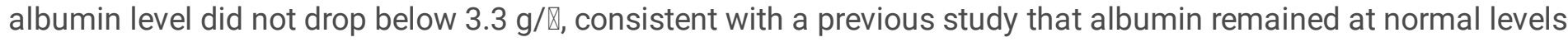
until the patients reached extreme starvation [54]. As mentioned above, serum albumin is affected by hydrostatic pressure, several inflammatory states, and drugs that affect hepatic function. Its long half-life of three weeks makes it less reliable as an indicator of malnutrition and the effect of nutritional intervention. Serum total protein is mostly composed of albumin and globulin and can easily change in inflammatory conditions. Hence, the current consensus is that serum albumin and total protein cannot be used reliably as markers for detecting malnutrition [4]

Leptin, a well-known regulator of energy balance, is synthesized in adipocytes and secreted into the circulation; serum levels of leptin strongly correlate with the amount of fat mass and BMI $[55,56]$. Leptin is also involved in the development of various cancers, including breast cancer and prostate cancer, which promote the migration and invasion of tumors by upregulating ACAT2 and STAT3, respectively $[25,57]$. Weryńska et al. reported that leptin levels were reduced in cancer patients with cachexia compared to patients without significant weight loss and normal controls [58]. In our study, there was no significant difference in leptin associated with chemotherapy, a previously study also showed no statistical change in patients with acute myeloid leukemia before and after chemotherapy [59].

Cytokines are secreted by infections, inflammatory conditions, and immune responses, and some cytokines are known to be associated with tumor development or progression. [60]. They also play a role in the induction of involuntary weight loss associated with inflammation and impair the homeostatic regulation of energy balance in cancer patients [61]. CXCL13, known as BCA-1 (B cell-attracting chemokine 1) or B-lymphocyte chemoattractant (BLC), has been identified as an attractant selective for $B$ lymphocytes. This chemokine, a subgroup of cytokines, is constitutively expressed in the follicles of Peyer's patches (PPs), spleen, and lymph nodes [62]. CXCL13 is involved in lymphoid neogenesis and pathogenesis of various diseases, including autoimmune diseases, inflammation, and cancer [26]. CXCL13 plays a role in cancer progression and the determination of the cancer cell phenotype. The serum content of CXCL13 is correlated with tumor diameter after chemotherapy [63]. Nagai et al. reported that CXCL13 expression in stromal cells within the bone marrow and intestine is regulated in response to nutritional status. They also proposed that CXCL13 may play a role as a mediator between immune response and energy metabolism. Naive B cells migrate from PPs to the bone marrow during fasting and then back to PPs during refeeding by regulating CXCL13 expression in PPs and bone marrow in mice [31]. Kim et al. also noted that a significant increase in plasma levels of CXCL13 was observed after 4 weeks of a high-fat diet in mice, which might induce the migration of B lymphocytes into PPs [64]. These results suggest that CXCL13 expression is involved in the maintenance of gut immune homeostasis by proliferating and differentiating $B$ cells according to their nutritional state [31, 38]. Furthermore, CXCL13 expression is increased in white adipose tissue from high-fat diet-fed mice [65]. White adipose tissue is important for maintaining the energy balance in cancer patients receiving chemotherapeutic agents. Loss of adipose tissue in cancer patients is highly associated with poor survival and reduced quality-of-life [66]. In our study, undernourished patients who reported weight loss showed a continuous decrease in serum CXCL13 levels during the study period, suggesting that this change may lead to problems of gut immune function and white adipose tissue.

Growth/differentiation factor-15 (GDF-15), a member of the transforming growth factor $\beta$ (TGF- $\beta$ ), is hardly detectable in humans under normal conditions, but it is highly expressed under stress conditions, including inflammation, injury, and cancer [67]. In patients with acute myeloid leukemia, GDF15 secreted by leukemic cells

Page 14/24 
may be associated with poor prognosis by increasing morphological remodeling of marrow adipocytes, stimulating leukemic cell growth [68]. GDF15 modulates energy balance by triggering conditioned taste aversion [69], and neutralization of GDF-15 reduces chemotherapy-induced emesis, anorexia, and weight loss in animal studies [70]. The correlations between higher GDF15 plasma levels and loss of body mass in individuals with advanced cancers and with reduced BMI in healthy twins imply that GDF15 also plays a role in the regulation of body weight in humans [32]. Serum GDF-15 levels are elevated by platinum-based chemotherapy such as cisplatin and oxaliplatin. This causes anorexia and subsequent weight loss by inducing nausea and emesis [70,71]. These previous studies support our finding that significant increases in serum GDF15 in the ROI and IPF groups. The increase in GDF15 in the IPF group may be due to more than half of patients in two groups overlapping in the two groups.

Our study has some limitations. First, our study was conducted in a single institution with a small number of participants. The number of participants was limited because of the difficulty in serial lab evaluation. This type of problem can be solved through multicenter research in the future. Second, the patient population was limited to hematologic cancer. Conversely, since our study was performed in a homogenous group, more accurate energy balance information could be obtained in patients with hematologic malignancy. Finally, this is a relatively short period of study. However, this allowed us to determine the changes in energy balance parameters and laboratory markers shortly after chemotherapy through weekly follow-up. Further studies will be able to accurately determine the correlation between the energy balance components and serum biomarkers in patients with hematologic cancer.

\section{Conclusion}

The current study results indicated that $65 \%$ of patients with hematologic cancer suffered from energy imbalances during chemotherapy associated with weight loss and anorexia. Significant alterations in CXCL13 and GDF15 were observed. The subgroup analysis suggested that serum CXCL13 levels could be associated with weight loss while serum GDF15 level is related to loss of appetite. Monitoring the energy balance through clinical and serum biomarkers together helps to quickly identify the need for symptom management or nutritional intervention in patients undergoing chemotherapy. Further multi-institutional studies will be needed to analyze the long-term effect of energy state and verify that serum CXCL13 and GDF15 will be novel biomarkers for the early detection of high risk of malnutrition in cancer patients.

\section{Abbreviations}

REE: resting energy expenditure; TEF: thermic effect of food; AEE: activity energy expenditure; QoL: quality-of-life; FFM: fat free mass; IC: indirect calorimetry; HBEq: Harris-Benedict equation; PG-SGA: Patient-Generated Subjective Global Assessment; EORTC QLQ-C30: European Organization for Research and Treatment of Cancer Quality-of-Life Core Questionnaire 30 version 3.0; EQ5D: EuroQol-5 dimension; HB: Harris-Benedict; PSU: Penn State University; BMR: Basic Metabolic Rate; DEMMI: de Morton Mobility Index; CXCL13: CXC Motif Chemokine Ligand 13; GDF15: Growth/differentiation factor-15; HSCT: Hematopoietic stem cell transplantation; SWL: significant weight loss; ROI: reduced oral intake; IPF: impaired physical function; BMI: body mass index; TEE: Total energy expenditure; W3: week three; W1: week one; W2: week two; TGF- $\beta$ : transforming growth factor $\beta$

\section{Declarations}




\section{Ethics approval and consent to participate}

The study was approved by the Institutional Review Board of Seoul National University Hospital, BIOMEDICAL RESEARCH INSTITUTE (Seoul, Korea). Written informed consent was obtained from all patients in the study.

\section{Consent for publication}

Not applicable.

\section{Availability of data and materials}

The datasets used during the current study are available from the corresponding author on reasonable request.

All methods were carried out in accordance with relevant guidelines and regulations

\section{Competing interests}

The authors declare that they have no competing interests.

\section{Funding}

This work was supported by a National Research Foundation of Korea (NRF) grant funded by the Korea government (MSIT) (No. 2018R1A2B6001296).

\section{Authors' contributions}

CWL and KSS initiated the study and collected data with input from IK, YK, DS, and JH. DK and MP conducted the laboratory tests and analyses. CWL analyzed and interpreted the patient data regarding energy balance and was a major contributor in writing the manuscript. SH and YL collaborated on drafting the manuscript. KSS revised it critically for important intellectual content. All authors read and approved the final manuscript.

\section{Acknowledgements}

We would like to thank Editage (www.editage.co.kr) for English language editing.

\section{Authors' information}

1Department of Rehabilitation Medicine, Seoul National University College of Medicine, Seoul National University Hospital, Seoul, Republic of Korea; 2 Department of Internal Medicine, Seoul National University College of Medicine, Seoul National University Hospital, Seoul, Republic of Korea; 3Department of Pharmacology, Korea University College of Medicine, Seoul, Republic of Korea; 4Department of Biomedical Sciences, Korea University College of Medicine, Seoul, Republic of Korea 


\section{References}

1. Pi-Sunyer FX. The obesity epidemic: pathophysiology and consequences of obesity. Obes Res. 2002;10; Suppl 2:97S-104S.

2. Hall KD, Heymsfield SB, Kemnitz JW, Klein S, Schoeller DA, Speakman JR. Energy balance and its components: implications for body weight regulation. Am J Clin Nutr. 2012;95(4):989-94.

3. Hill JO, Wyatt HR, Peters JC. Energy balance and obesity. Circulation. 2012;126(1):126-32.

4. Bharadwaj S, Ginoya S, Tandon P, Gohel TD, Guirguis J, Vallabh H, et al. Malnutrition: laboratory markers vs nutritional assessment. Gastroenterol Rep (Oxf). 2016;4(4):272-80.

5. Davis MP, Dreicer R, Walsh D, Lagman R, LeGrand SB. Appetite and cancer-associated anorexia: a review. J Clin Oncol. 2004;22(8):1510-7.

6. Huhmann MB, Cunningham RS. Importance of nutritional screening in treatment of cancer-related weight loss. Lancet Oncol. 2005;6(5):334-43.

7. Hébuterne X, Lemarié E, Michallet M, de Montreuil CB, Schneider SM, Goldwasser F. Prevalence of malnutrition and current use of nutrition support in patients with cancer. JPEN J Parenter Enteral Nutr. 2014;38(2):196-204.

8. Sinno MH, Coquerel Q, Boukhettala N, Coëffier M, Gallas S, Terashi M, et al. Chemotherapy-induced anorexia is accompanied by activation of brain pathways signaling dehydration. Physiol Behav. 2010;101(5):639-48.

9. Nicolini A, Ferrari P, Masoni MC, Fini M, Pagani S, Giampietro O, et al. Malnutrition, anorexia and cachexia in cancer patients: a mini-review on pathogenesis and treatment. Biomed Pharmacother. 2013;67(8):807-17.

10. Fearon K, Strasser F, Anker SD, Bosaeus I, Bruera E, Fainsinger RL, et al. Definition and classification of cancer cachexia: an international consensus. Lancet Oncol. 2011;12(5):489-95.

11. Michallet M, Hollard D, Guignier AM, La Verve X, Laturaze J. Parenteral nutrition in patients with leukemia and non-Hodgkin malignant lymphoma under chemotherapy. JPEN J Parenter Enteral Nutr. 1979;3(4):247-54.

12. Suzuki H, Asakawa A, Amitani H, Nakamura N, Inui A. Cancer cachexia-pathophysiology and management. J Gastroenterol. 2013;48(5):574-94.

13. Costa LJM, Varella PCS, Giglio A. Weight changes during chemotherapy for breast cancer. Sao Paulo Med. J. 2002;120:113-7.

14. Van Soom T, El Bakkali S, Gebruers N, Verbelen H, Tjalma W, van Breda E. The effects of chemotherapy on energy metabolic aspects in cancer patients: A systematic review. Clin Nutr. 2020;39(6):1863-77.

15. Haugen HA, Chan LN, Li F. Indirect calorimetry: a practical guide for clinicians. Nutr Clin Pract. 2007;22(4):37788.

16. Flancbaum L, Choban PS, Sambucco S, Verducci J, Burge JC. Comparison of indirect calorimetry, the Fick method, and prediction equations in estimating the energy requirements of critically ill patients. Am J Clin Nutr. 1999;69(3):461-6.

17. Douglas CC, Lawrence JC, Bush NC, Oster RA, Gower BA, Darnell BE. Ability of the Harris Benedict formula to predict energy requirements differs with weight history and ethnicity. Nutr Res. 2007;27(4):194-9.

18. Mehta NM, Smallwood CD, Joosten KF, Hulst JM, Tasker RC, Duggan CP. Accuracy of a simplified equation for energy expenditure based on bedside volumetric carbon dioxide elimination measurement-a two-center study. Clin Nutr. 2015;34(1):151-5. 
19. Mazzo R, Ribeiro FB, Vasques ACJ. Accuracy of predictive equations versus indirect calorimetry for the evaluation of energy expenditure in cancer patients with solid tumors - An integrative systematic review study. Clin Nutr ESPEN. 2020;35:12-9.

20. Cereda E, Turrini M, Ciapanna D, Marbello L, Pietrobelli A, Corradi E. Assessing energy expenditure in cancer patients: a pilot validation of a new wearable device. JPEN J Parenter Enteral Nutr. 2007;31(6):502-7.

21. Lerebours E, Tilly H, Rimbert A, Delarue J, Piguet H, Colin R. Change in energy and protein status during chemotherapy in patients with acute leukemia. Cancer. 1988;61(12):2412-7.

22. Harris JA, Benedict FG. A biometric study of human basal metabolism. Proc Natl Acad Sci US A. 1918;4(12):370-3.

23. Frankenfield D, Smith JS, Cooney RN. Validation of 2 approaches to predicting resting metabolic rate in critically ill patients. JPEN J Parenter Enteral Nutr. 2004;28(4):259-64.

24. Arends J, Bachmann P, Baracos V, Barthelemy N, Bertz H, Bozzetti F, et al. ESPEN guidelines on nutrition in cancer patients. Clin Nutr. 2017;36(1):11-48.

25. Huang Y, Jin Q, Su M, Ji F, Wang N, Zhong C, et al. Leptin promotes the migration and invasion of breast cancer cells by upregulating ACAT2. Cell Oncol (Dordr). 2017;40(6):537-47.

26. Kazanietz MG, Durando M, Cooke M. CXCL13 and its receptor CXCR5 in cancer: inflammation, immune response, and beyond. Front Endocrinol (Lausanne). 2019 Jul 12;10:471.

27. Li S, Ma YM, Zheng PS, Zhang P. GDF15 promotes the proliferation of cervical cancer cells by phosphorylating AKT1 and ERK1/2 through the receptor ErbB2. J Exp Clin Cancer Res. 2018;37(1):80.

28. Wischhusen J, Melero I, Fridman WH. Growth/differentiation factor-15 (GDF-15): from biomarker to novel targetable immune checkpoint. Front Immunol. 2020;11:951.

29. Zhao D, Wang X, Zhang W. GDF15 predict platinum response during first-line chemotherapy and can act as a complementary diagnostic serum biomarker with CA125 in epithelial ovarian cancer. BMC Cancer. 2018;18(1):328.

30. Kusuyama J, Komorizono A, Bandow K, Ohnishi T, Matsuguchi T. CXCL3 positively regulates adipogenic differentiation. J Lipid Res. 2016;57(10):1806-20.

31. Nagai M, Noguchi R, Takahashi D, Morikawa T, Koshida K, Komiyama S, et al. Fasting-refeeding impacts immune cell dynamics and mucosal immune responses. Cell. 2019;178(5):1072-1087.e14.

32. Yang L, Chang CC, Sun Z, Madsen D, Zhu H, Padkjær SB, et al. GFRAL is the receptor for GDF15 and is required for the anti-obesity effects of the ligand. Nat Med. 2017;23(10):1158-66.

33. Jager-Wittenaar $\mathrm{H}$, Ottery FD. Assessing nutritional status in cancer: role of the Patient-Generated Subjective Global Assessment. Curr Opin Clin Nutr Metab Care. 2017;20(5):322-9.

34. Aaronson NK, Ahmedzai S, Bergman B, Bullinger M, Cull A, Duez NJ, et al. The European Organization for Research and Treatment of Cancer QLQ-C30: a quality-of-life instrument for use in international clinical trials in oncology. J Natl Cancer Inst. 1993;85(5):365-76.

35. Balestroni G, Bertolotti G. [EuroQol-5D (EQ-5D): an instrument for measuring quality of life]. Monaldi Arch Chest Dis. 2012;78(3):155-9.

36. Lee YK, Nam HS, Chuang LH, Kim KY, Yang HK, Kwon IS, et al. South Korean time trade-off values for EQ-5D health states: modeling with observed values for 101 health states. Value Health. 2009;12(8):1187-93.

37. Ohnuma T, Holland JF. Nutritional consequences of cancer chemotherapy and immunotherapy. Cancer Res. 1977;37(7 Pt 2):2395-406.

Page 18/24 
38. Kim I, Koh Y, Shin D, Hong J, Do HJ, Kwon SH, et al. Importance of monitoring physical function for quality of life assessments in hematopoietic stem cell transplantation patients: a prospective cohort study. in vivo 2020. In Vivo. 2020;34(2):771-7.

39. Fearon KC, Voss AC, Hustead DS, Cancer Cachexia Study Group. Definition of cancer cachexia: effect of weight loss, reduced food intake, and systemic inflammation on functional status and prognosis. Am J Clin Nutr. 2006;83(6):1345-50.

40. Arends J, Bodoky G, Bozzetti F, Fearon K, Muscaritoli M, Selga G, et al. ESPEN guidelines on enteral nutrition: non-surgical oncology. Clin Nutr. 2006;25(2):245-59.

41. Bauer J, Capra S, Ferguson M. Use of the scored Patient-Generated Subjective Global Assessment (PG-SGA) as a nutrition assessment tool in patients with cancer. Eur J Clin Nutr. 2002;56(8):779-85.

42. Fukahori M, Shibata M, Hamauchi S, Kasamatsu E, Machii K. A retrospective cohort study to investigate the incidence of cancer-related weight loss during chemotherapy in gastric cancer patients. Support Care Cancer. 2021;29(1):341-8.

43. Sánchez-Lara K, Ugalde-Morales E, Motola-Kuba D, Green D. Gastrointestinal symptoms and weight loss in cancer patients receiving chemotherapy. Br J Nutr. 2013;109(5):894-7.

44. Le Bricon T, Gugins S, Cynober L, Baracos VE. Negative impact of cancer chemotherapy on protein metabolism in healthy and tumor-bearing rats. Metabolism. 1995;44(10):1340-8.

45. Petruzzelli M, Wagner EF. Mechanisms of metabolic dysfunction in cancer-associated cachexia. Genes Dev. 2016;30(5):489-501.

46. Schiessel DL, Baracos VE. Barriers to cancer nutrition therapy: excess catabolism of muscle and adipose tissues induced by tumour products and chemotherapy. Proc Nutr Soc. 2018;77(4):394-402.

47. Stein A, Voigt W, Jordan K. Chemotherapy-induced diarrhea: pathophysiology, frequency and guideline-based management. Ther Adv Med Oncol. 2010;2(1):51-63.

48. Bryant AL, Deal AM, Battaglini CL, Phillips B, Pergolotti M, Coffman E, et al. The effects of exercise on patientreported outcomes and performance-based physical function in adults with acute leukemia undergoing induction therapy: exercise and quality of life in acute leukemia (EQUAL). Integr Cancer Ther. 2018;17(2):26370.

49. Galati PC, Chiarello PG, Simões BP. Variation of resting energy expenditure after the first chemotherapy cycle in acute leukemia patients. Nutr Cancer. 2016;68(1):86-93.

50. Frankenfield DC, Ashcraft CM. Estimating energy needs in nutrition support patients. JPEN J Parenter Enteral Nutr. 2011;35(5):563-70.

51. Keller U. Nutritional laboratory markers in malnutrition. J Clin Med. 2019;8(6):775.

52. Soeters PB, Wolfe RR, Shenkin A. Hypoalbuminemia: pathogenesis and clinical significance. JPEN J Parenter Enteral Nutr. 2019;43(2):181-93.

53. Khan AM, Lancet JE, Kharfan-Dabaja MA, Al Ali NH, List AF, Komrokji RS. Albumin is a prognostic factor for overall survival in newly diagnosed patients with acute myeloid leukemia (AML). In: American Society of Hematology; 2011.

54. Lee JL, Oh ES, Lee RW, Finucane TE. Serum albumin and prealbumin in calorically restricted, nondiseased individuals: a systematic review. Am J Med. 2015;128(9): 1023.e1-22

55. Hursting SD, DiGiovanni J, Dannenberg AJ, Azrad M, LeRoith D, Demark-Wahnefried W, et al. Obesity, energy balance, and cancer: new opportunities for prevention. Cancer Prev Res (Phila). 2012;5(11):1260-72. 
56. Trinh T, Broxmeyer HE. Role for leptin and leptin receptors in stem cells During health and diseases. Stem Cell Rev Rep. 2021;17(2):511-22.

57. Gorrab A, Pagano A, Ayed K, Chebil M, Derouiche A, Kovacic H, et al. Leptin promotes prostate cancer proliferation and migration by stimulating STAT3 pathway. Nutr Cancer. 2021;73(7):1217-27.

58. Weryńska B, Kosacka M, Gołecki M, Jankowska R. Leptin serum levels in cachectic and non-cachectic lung cancer patients. Pneumonol Alergol Pol. 2009;77(6):500-6.

59. Yilmaz M, Kis C, Ceylan NO, Okan V, Pehlivan M, Kuçukosmanoglu E, et al. Serum leptin level in acute myeloid leukemia patients. Hematology. 2008;13(1):21-3.

60. Dranoff G. Cytokines in cancer pathogenesis and cancer therapy. Nat Rev Cancer. 2004;4(1):11-22.

61. Le Thuc O, Stobbe K, Cansell C, Nahon JL, Blondeau N, Rovère C. Hypothalamic inflammation and energy balance disruptions: spotlight on chemokines. Front Endocrinol. 2017;8:197.

62. Jenh $\mathrm{CH}, \mathrm{Cox}$ MA, Hipkin W, Lu T, Pugliese-Sivo C, Gonsiorek W, et al. Human B cell-attracting chemokine 1 (BCA-1; CXCL13) is an agonist for the human CXCR3 receptor. Cytokine. 2001;15(3):113-21.

63. Wei Y, Lin C, Li H, Xu Z, Wang J, Li R, et al. CXCL13 expression is prognostic and predictive for postoperative adjuvant chemotherapy benefit in patients with gastric cancer. Cancer Immunol Immunother. 2018;67(2):2619.

64. Kim D-H, Cho JM, Seo MJ, Lim JH, Bae H-R. Alteration in plasma chemokine profile in a high-fat diet-induced obesity mouse model. J Nutr Health. 2018;51(5):369-78.

65. Kusuyama J, Bandow K, Ohnishi T, Amir MS, Shima K, Semba I, et al. CXCL13 is a differentiation- and hypoxiainduced adipocytokine that exacerbates the inflammatory phenotype of adipocytes through PHLPP1 induction. Biochem J. 2019;476(22):3533-48.

66. Ebadi M, Field CJ, Lehner R, Mazurak VC. Chemotherapy diminishes lipid storage capacity of adipose tissue in a preclinical model of colon cancer. Lipids Health Dis. 2017;16(1):247.

67. Tsai VWW, Husaini Y, Sainsbury A, Brown DA, Breit SN. The MIC-1/GDF15-GFRAL pathway in energy homeostasis: implications for obesity, cachexia, and other associated diseases. Cell Metab. 2018;28(3):35368.

68. Lu W, Wan Y, Li Z, Zhu B, Yin C, Liu H, et al. Growth differentiation factor 15 contributes to marrow adipocyte remodeling in response to the growth of leukemic cells. J Exp Clin Cancer Res. 2018;37(1):66.

69. Patel S, Alvarez-Guaita A, Melvin A, Rimmington D, Dattilo A, Miedzybrodzka EL, et al. GDF15 provides an endocrine signal of nutritional stress in mice and humans. Cell Metab. 2019;29(3):707-718.e8. e708.

70. Breen DM, Kim H, Bennett D, Calle RA, Collins S, Esquejo RM, et al. GDF-15 neutralization alleviates platinumbased chemotherapy-induced emesis, anorexia, and weight loss in mice and nonhuman primates. Cell Metab. 2020;32(6):938-950.e6. e936.

71. Borner T, Shaulson ED, Ghidewon MY, Barnett AB, Horn CC, Doyle RP, et al. GDF15 induces anorexia through nausea and emesis. Cell Metab. 2020;31(2):351-362.e5. e355.

\section{Figures}




\section{Admission $(n=40)$}

\begin{tabular}{|ll|}
\hline- & At Baseline \\
$\checkmark$ & PG-SGA \\
$\checkmark$ & QLQ-C30 \\
$\checkmark$ & EQ-5D \\
\hline
\end{tabular}

\section{Receiving chemotherapy}

Discharge $(n=40)$

\section{- At Baseline, Week 1, Week 2, Week 3}

1) Energy balance

$\checkmark$ Overall (body weight), intake (oral, parental, total), Expenditure (REE-HB\&PSU, DEMMI, daily steps)

2) Laboratory findings

$\checkmark$ Serum total protein, albumin, and biomarker candidates (CXCL13, GDF15, Leptin)

\section{Figure 1}

Participation and patient flow chart of the 40 patients with hematologic cancer

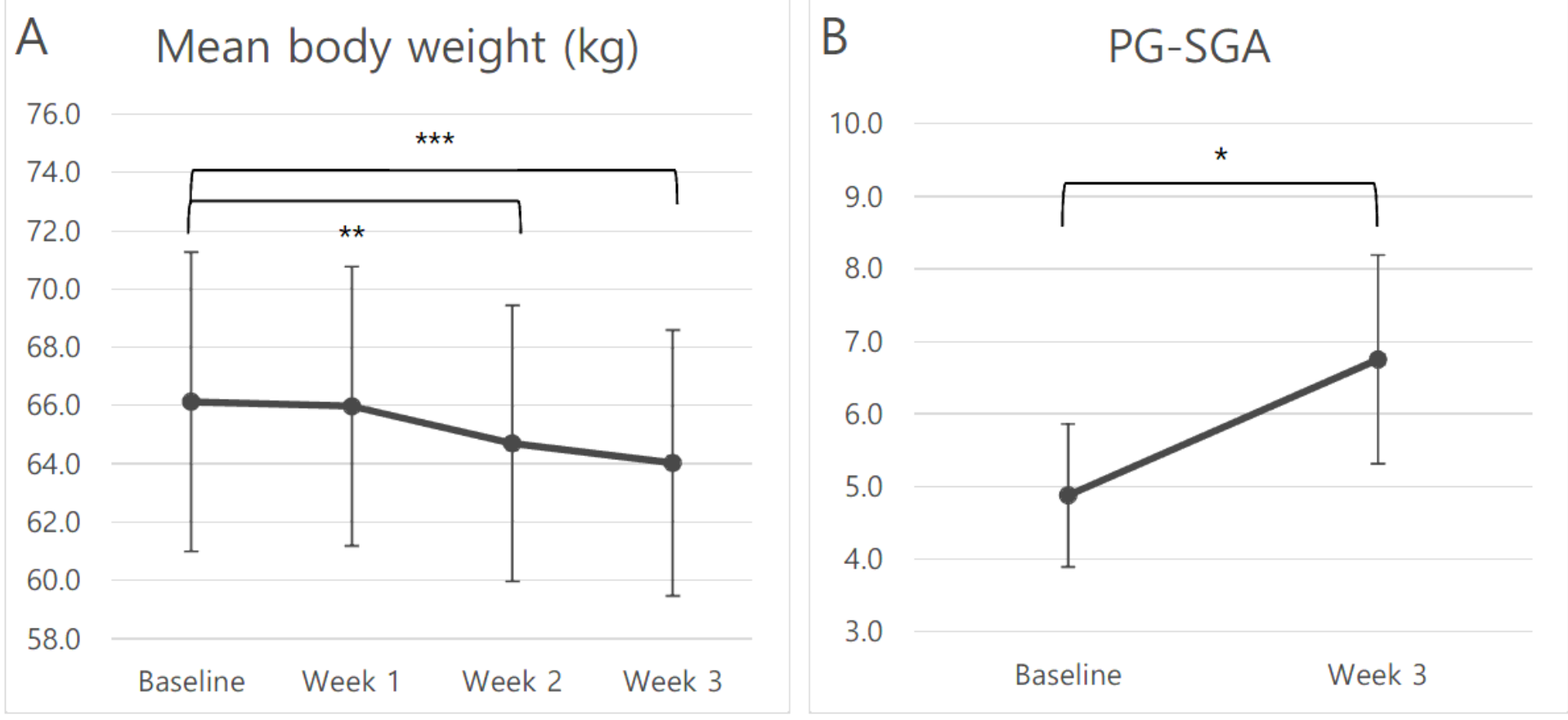

Figure 2

Changes in the mean (a) body weight and (b) PG-SGA score in total participants $(n=40)$. The error bars represent the $95 \%$ confidence interval of the mean values. PG-SGA, Patient-Generated Subjective Global Assessment *Pvalue $<0.05, * \star<0.01, * \star *<0.001$ 


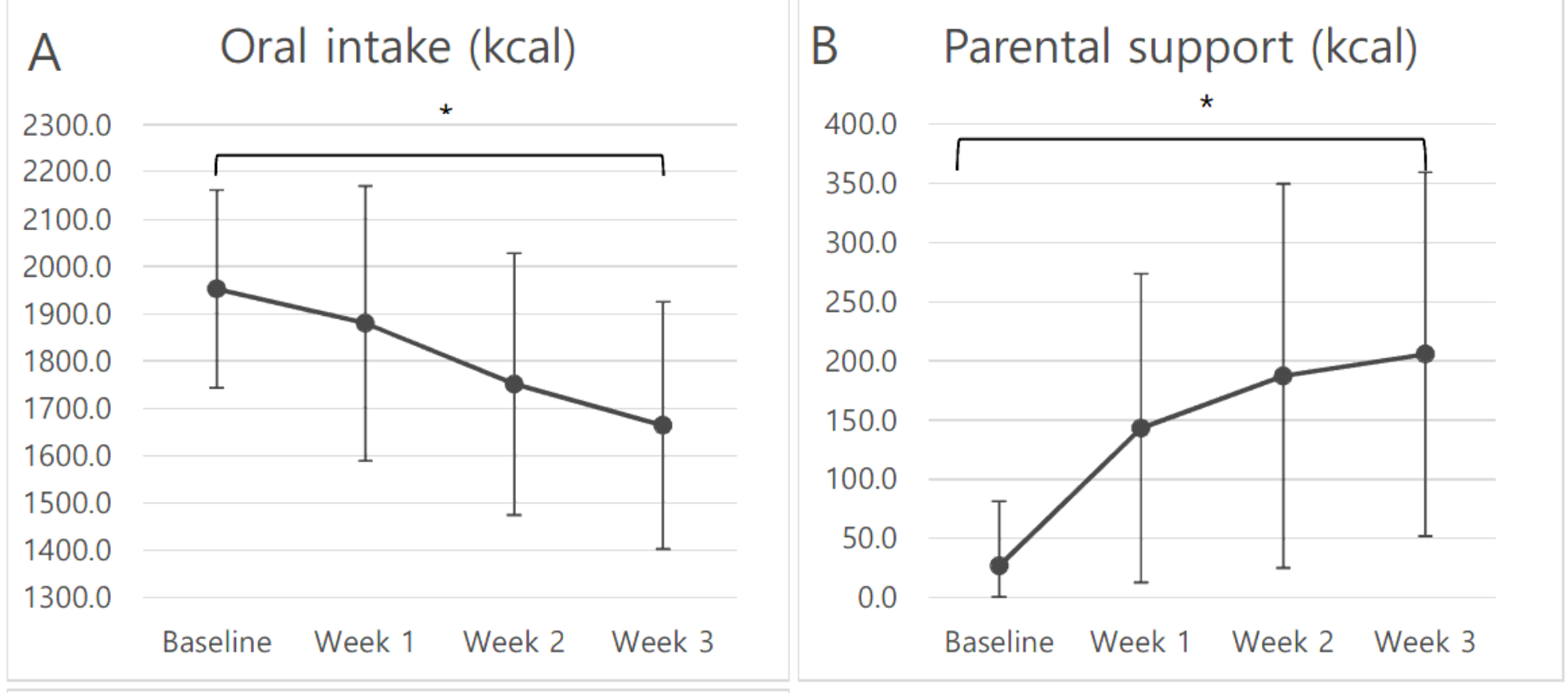

\section{Total intake (kcal)}

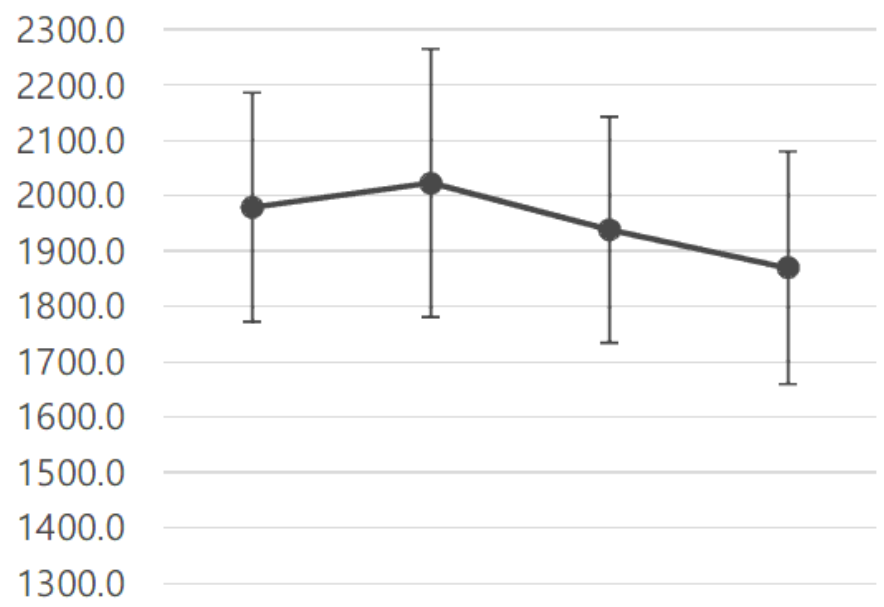

Baseline Week 1 Week 2 Week 3

\section{Figure 3}

Changes of mean value of daily energy intake components, related to (a) oral intake, (b) parental support, and (c) total intake in total participants $(n=40)$. The error bars represent the $95 \%$ confidence interval of the mean values. * P-value $<0.05$ 


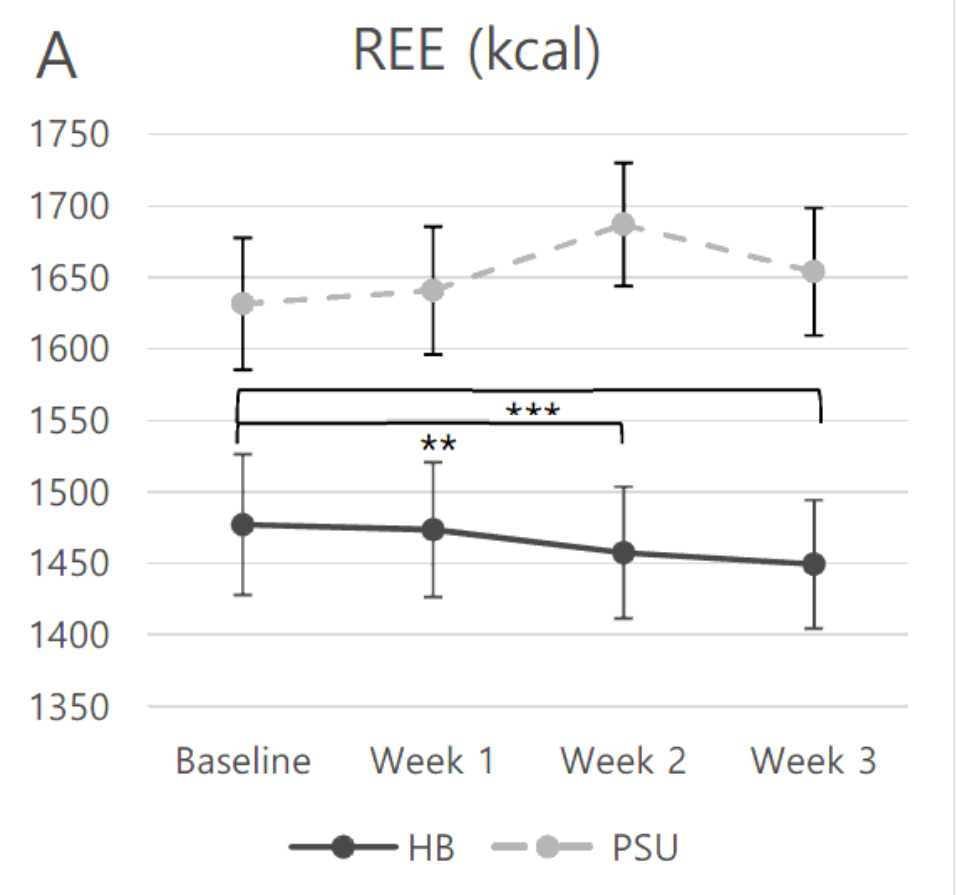

B DEMMI

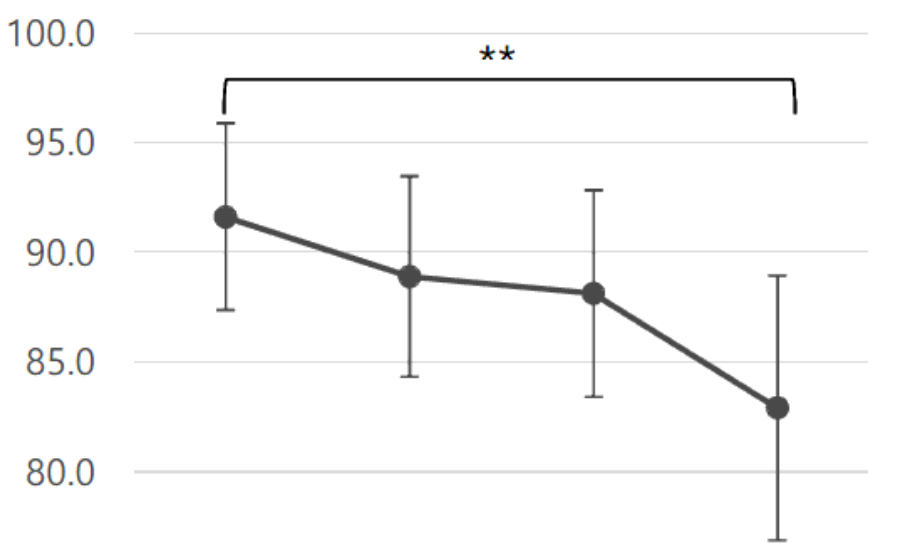

75.0

70.0

Baseline Week 1 Week 2 Week 3

\section{Figure 4}

Changes in the mean value of (a) daily REE and (b) DEMMI score of total participants $(n=40)$. REE was calculated according to HB and PSU equations. The error bars represent the $95 \%$ confidence interval of the mean values. REE, resting energy expenditure; HB, Harris-Benedict; PSU, Penn State University; DEMMI, de Morton Mobility Index ** Pvalue $<0.01, * * *<0.001$ 


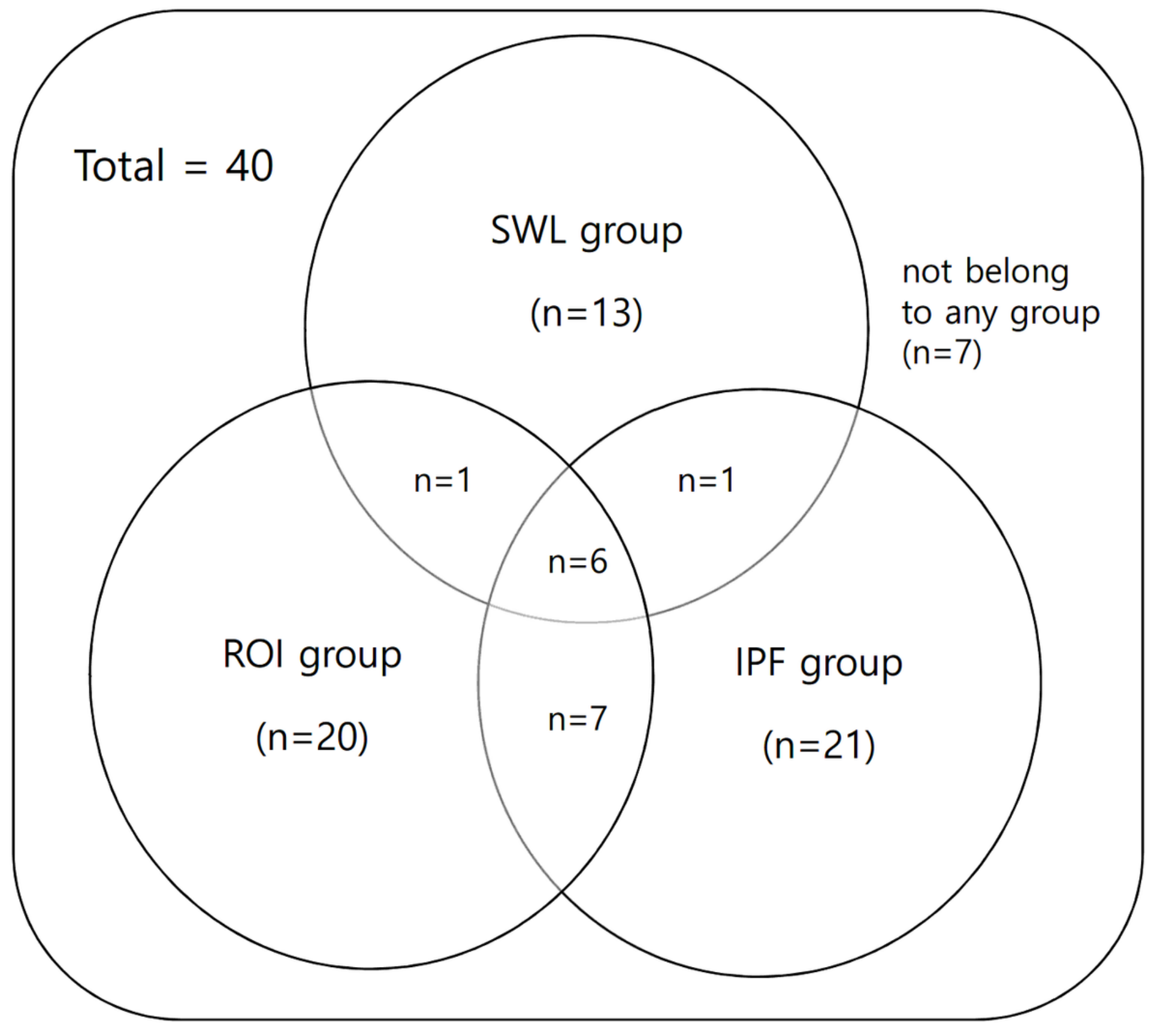

Figure 5

Venn diagram of subgroup classifications. SWL, significant weight loss; ROI, reduced oral intake; IPF, impaired physical function 